\title{
Experimental model of intracranial hypertension with continuous multiparametric monitoring in swine
}

\author{
Modelo Experimental de Hipertensão Intracraniana com \\ monitorização multiparamétrica contínua em suínos \\ Almir Ferreira de Andrade1, Matheus Schmidt Soares', Gustavo Cartaxo Patriota², \\ Alessandro Rodrigo Belon², Wellingson Silva Paiva', Edson Bor-Seng-Shu', Marcelo de Lima Oliveira', \\ Clarissa Nóbrega Nascimento', Gustavo Sousa Noleto', Aderaldo Costa Alves Junior², Eberval Gadelha \\ Figueiredo ${ }^{1}$, José Pinhata Otoch², Manoel Jacobsen Teixeira ${ }^{1}$
}

\begin{abstract}
Objective: Intracranial hypertension (IH) develops in approximately $50 \%$ of all patients with severe traumatic brain injury (TBI). Therefore, it is very important to identify a suitable animal model to study and understand the pathophysiology of refractory IH to develop effective treatments. Methods: We describe a new experimental porcine model designed to simulate expansive brain hematoma causing IH. Under anesthesia, IH was simulated with a balloon insufflation. The IH variables were measured with intracranial pressure (ICP) parenchymal monitoring, epidural, cerebral oximetry, and transcranial Doppler (TCD). Results: None of the animals died during the experiment. The ICP epidural showed a slower rise compared with parenchymal ICP. We found a correlation between ICP and cerebral oximetry. Conclusion: The model described here seems useful to understand some of the pathophysiological characteristics of acute $\mathrm{IH}$.
\end{abstract}

Keywords: experimental model, intracranial hypertension, transcranial doppler sonography.

RESUMO

Objetivo: A hipertensão intracraniana (HIC) ocorre em até 50\% de todos os pacientes com traumatismo cranioencefálico (TCE). Por isso, é importante estabelecer um modelo animal adequado para estudar a fisiopatologia da HIC refratária, com a perspectiva de desenvolver tratamentos eficazes. Métodos: Os animais foram submetidos a um protocolo padrão de anestesia. A hipertensão intracraniana foi estabelecida através de insuflação de um balão. As variáveis HIC foram medidas com a pressão intracraniana (PIC) do parênquima, oximetria, epidural e doppler transcraniano. Resultados: A PIC epidural apresentou elevação mais lenta, comparada com a PIC parenquimal. Houve correlação entre a PIC e a oximetria cerebral. O registro da PIC, oximetria e índice de pulsatilidade foi realizado em todos os animais sem dificuldade. Conclusão: $O$ modelo descrito parece ser útil para a compreensão de algumas características fisiopatológicas na HIC aguda.

Palavras-chave: pressão intracraniana, ultrassonografia, doppler transcraniana, modelos experimentais.

Intracranial hypertension (IH) develops in approximately $50 \%$ of all patients with severe traumatic brain injury (TBI) and is more common in patients with intracranial hematoma $(\mathrm{ICH})^{1,2}$. Therefore, it is very important to identify a suitable animal model to study and understand the pathophysiology of refractory IH to develop effective treatments.
Many models of neurosurgical experiments in small animals, such as rats and cats, have been developed; however, compared to humans, they have smaller brain volumes and more distinct behaviors ${ }^{3,4}$. While there are existing porcine models, they simulate ICH by infusing autologous blood into the brain tissue and do not replicate intracranial lesions ${ }^{3-6}$.

${ }^{1}$ Division of Neurosurgery, University of São Paulo Medical School, São Paulo SP, Brazil;

LIM 26, Experimental Surgery Laboratory, University of São Paulo Medical School, São Paulo SP, Brazil.

Correspondence: Wellingson Paiva; Rua Eneas Aguiar 255 / 4080; 0543-010 São Paulo SP - Brasil; E-mail:wellingsonpaiva@yahoo.com.br

Conflict of interest: There is no conflicts of interest to declare.

Received 04 March 2013; Received in final form 24 May 2013; Accepted 31 May 2013. 
Here, we describe a new experimental model designed to simulate expansive brain hematoma causing IH by using an infusion pump to progressively inflate an intracerebral balloon; the lesion can be easily relieved via cuff deflation.

\section{METHODS}

This protocol was approved by the Research Ethics Committee of the Hospital das Clinicas - University of Sao Paulo Medical School.

\section{Animals}

We obtained 2-month old crossbred Landrace and Duroc pigs weighing approximately $18-20 \mathrm{~kg}$ from a private farm located in Suzano, Brazil; they were delivered to the University of Sao Paulo Veterinary School and transported to the medical school on the day of the experiment.

\section{Anesthesia protocol}

Prior to surgery, pigs were fasted for $12 \mathrm{~h}$ but had free access to water. We then co-administered intramuscular ketamine (Ketamin-S ${ }^{\circledR}$, Cristália) at a dose of $15 \mathrm{mg} / \mathrm{kg}$ and xylazine (Anasedan ${ }^{\circledR}$, Ceva) at a dose of $2 \mathrm{mg} / \mathrm{kg}$ as a preanesthetic. Once intravenous (IV) access was obtained, anesthesia was induced with propofol (1\% Provine ${ }^{\circledR}$, Claris) at a dose of $5 \mathrm{mg} / \mathrm{kg}$. The animals also received an initial IV volume of $20 \mathrm{ml} / \mathrm{kg}$ physiological saline ( $\mathrm{NaCl} 0.9 \%$ ) to compensate for volume loss due to fasting, and fluid support was continued throughout at a rate of $5 \mathrm{ml} / \mathrm{kg} / \mathrm{h}$. Anesthesia was maintained with IV propofol (1\% Provine $\left.{ }^{\circledR}\right)$ at a dose of $5-10 \mathrm{mg} / \mathrm{kg} / \mathrm{h}$, and IV fentanyl was given for analgesia (Fentanest ${ }^{\circledR}$, Cristália) at a starting dose of $5 \mu \mathrm{g} / \mathrm{kg}$ followed by continuous IV infusion of $0.08-0.15 \mathrm{mg} / \mathrm{kg} / \mathrm{min}$.

After endotracheal intubation, the animals were mechanically ventilated by controlled volume (Fan Dixtal ${ }^{\circledR} 5010$ ), tidal volume (VT) of $10 \mathrm{ml} / \mathrm{kg}$, fraction of inspired oxygen $\left(\mathrm{FiO}_{2}\right)$ of 0.40 , and positive end expiratory pressure (PEEP) of $5 \mathrm{cmH}_{2} \mathrm{O}$. The ventilatory parameters were adjusted to maintain partial pressure of carbon dioxide $\left(\mathrm{PaCO}_{2}\right)$ between 35 and $40 \mathrm{mmHg}$, partial pressure of oxygen $\left(\mathrm{PaO}_{2}\right)$ between 100 and $150 \mathrm{mmHg}$, and blood pH between 7.35 and 7.45. To assess ventilation adequacy, we continuously measured final pressure of end-tidal carbon dioxide $\left(\mathrm{EtCO}_{2}\right)$, peripheral hemoglobin saturation by pulse oximetry $\left(\mathrm{SpO}_{2}\right)$, and arterial blood gas samples $(0.3 \mathrm{ml})$. The right femoral artery was catheterized for invasive monitoring of mean blood pressure (MBP). Six arterial blood gas samples were obtained after additional interventions to ensure maintenance of physiological parameters. We also collected 5-ml serum samples to measure ubiquitin-C and beta amyloid precursor protein (SAA) levels. Hemodynamic data were collected and measured with a multiparameter Dixtal Monitor ${ }^{\circledR} 2020$.
Animal core temperature was maintained between $37^{\circ} \mathrm{C}$ and $39^{\circ} \mathrm{C}$ with the use of a blanket and previously heated maintenance solutions.

\section{Experimental model preparation}

An "L"-shaped skin incision was made at the sagittal midline to expose the coronal and sagittal sutures (Figure 1), and we made two 3-mm trephinations to install the balloon and multiparameter oximetry catheter. Two trephinations were also made in the middle fossa; the posterior one was for the intracranial pressure (ICP) epidural catheter (microsensor-type microchip, Neurodur ${ }^{\circledR}$; Raumedic, Germany), and the anterior one was used as a window for the transcranial Doppler (TCD) transducer. A trephination located 1-cm lateral to the metopic suture and anterior to the coronal suture allowed installation of a multiparameter catheter cerebral tissue oximetry sensor (microsensor-type microchip, Neurovent-PTiO ${ }^{\circledR}$; Raumedic) 1.5 -cm deep in the frontal lobe. A trepanation located 1-cm lateral to the sagittal suture and $1-\mathrm{cm}$ posterior to the coronal suture was performed to introduce a pediatric 8-French bladder catheter to a depth of $2 \mathrm{~cm}$ in the parietal lobe for accessing the parietal subcortical white matter.

\section{Algorithm experiment}

Through the continuous infusion pump, the cuff(balloon) of the pediatric catheter was progressively filled with $0.9 \%$ saline solution over $15 \mathrm{~min}$. In Group A, we infused $4 \mathrm{ml} \mathrm{sa-}$ line; in Group B, an additional $3 \mathrm{ml}$ was infused over $15 \mathrm{~min}$ at $1 \mathrm{~h}$ after the first infusion to simulate a rebleed; and in Group C, $7 \mathrm{ml}$ was infused over $15 \mathrm{~min}$. This fluid system was

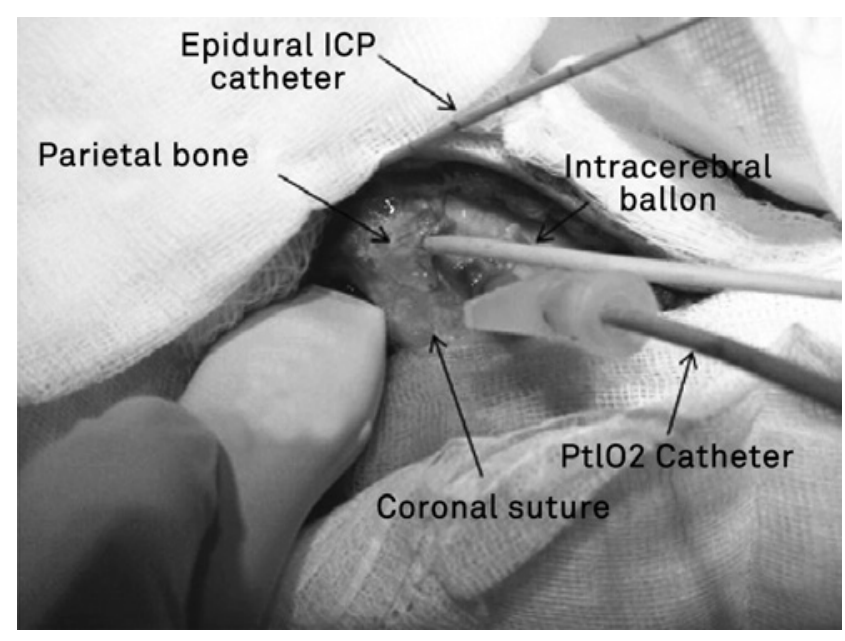

Figure 1. Figure of experimental model during the procedure. We performed two 3-mm trephinations with a balloon and multiparameter oximetry catheter (PtiO2). Two trephinations were also made in the middle fossa; the posterior one was for the intracranial pressure (ICP) epidural catheter (microsensortype microchip, Neurodur ${ }^{\circledR}$; Raumedic, Germany), and the anterior one was used as a window for the transcranial doppler (TCD) transducer. 
tested with the final volume of $0.9 \%$ saline solution prior to insertion into the parietal lobe. After complete catheter installation and balloon inflation, the model was maintained without intervention for $1 \mathrm{~h}$ until animal physiological parameters were stabilized.

The average weight of an adult human brain is $1350 \mathrm{~g}^{6}$, and those of the pigs used ( 2 months and $20 \mathrm{~kg}$ ) were $75 \mathrm{~g}$, which corresponds to $5.5 \%$ of the weight of the human brain. Thus, the 4-ml volume in Group A corresponded to a lesion of $72.7 \mathrm{ml}$ in the adult human brain. In the other two groups, the final volume of $7 \mathrm{ml}$ corresponded to a lesion of $127.3 \mathrm{ml}$.

After the first hour of calibration and parameter stabilization, the balloon was inflated by using the continuous infusion pump (Braun B Infusomat compact ${ }^{\circledR}$ ) over $15 \mathrm{~min}$. After $1.5 \mathrm{~h}, 3 \%$ hypertonic saline solution $3 \%(5.3 \mathrm{ml} / \mathrm{kg})$ was administered. After $30 \mathrm{~min}$, the pigs underwent surgery, and the balloon was deflated. The experiment ended after an additional hour during which the physiological parameters were observed. At each intervention, we performed a neurological assessment of the pupils and duplex with a Doppler apparatus (SonoSite - Micromax model) by using a sector transducer of 4-8 $\mathrm{mHz}$ through the right temporal trephination over the intracerebral artery according to the color flow technique, followed by Doppler blood flow velocity measurement (Figure 2).

At the end of the experiment, the animals were sacrificed via an IV overdose of propofol (20 mg/kg) and fentanyl (10 $\mathrm{mg} / \mathrm{kg}$ ) followed by $40 \mathrm{ml} 19.1 \%$ potassium chloride solution. The brain was then surgically removed, weighed on a high-precision balance, and sectioned to exclude the possibility of other cerebral bleeds.

\section{Animal disposal}

The pigs were placed in white plastic Biohazard bags with labels that clearly identified the origin, content, and responsible researcher. They were then transported to the hospital to be incinerated.

\section{RESULTS}

We have tested this pilot model in six animals and were able to identify correlations between progressive ICP increases and balloon inflation (Table 1). In a preliminary analysis of data from the first six animals, we observed stable systemic parameters, including blood pressure, arterial blood gases, heart rate, and oxygen saturation. We verified that parenchymal pressure rises and falls faster compared with epidural pressure. None of the animals died during the experiment, and there were no complications, which indicates that our method is safe. We clinically evaluated the animals throughout and monitored their pupillary responses to each phase of the experiment. In all animals, we verified pupillary response with anisocoria following increased ICP after balloon inflation, as well as reversal of this pattern when the balloon was deflated; this indicated a pattern of brain complacency and a clinical response to uncal herniation, similar to what is observed in the human brain. We also found a correlation between ICP and cerebral oximetry. Our results suggest that this is a reproducible experimental model.

\section{DISCUSSION}

In this study, we developed a new experimental model of ICH in pigs with lesion based on the Monro-Kellie doctrine ${ }^{1}$, which posits that the intracranial content is incompressible and has a constant volume. In the presence of ICH, the vascular space may decrease by $50 \%$; intracellular space could shrink to decrease total brain volume, and cerebrospinal fluid (CSF) production and absorption might decrease and increase, respectively.

Kim et al. ${ }^{10}$ recently reported that changes in intracranial venous, arterial, and CSF compartments could be mathematically estimated using serial analysis, allowing the calculation of a cerebral complacency index (CCI) as a correlation coefficient of changes in compartments. The authors
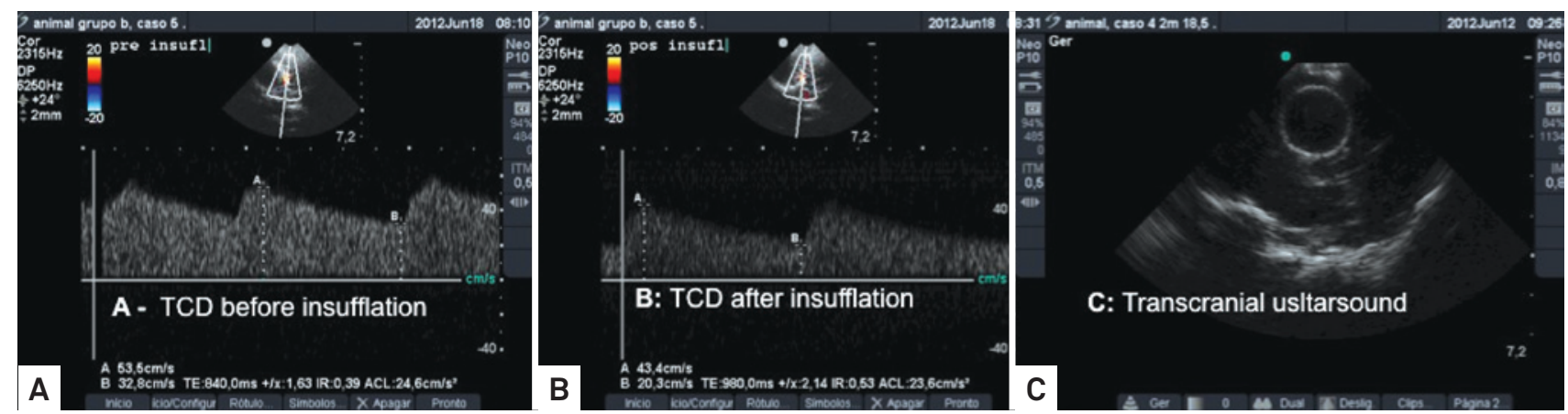

Figure 2. SonoSite - Micromax model using a sector transducer of $4-8 \mathrm{mHz}$ through the right temporal trephination over the intracerebral artery according to the color flow technique, followed by Doppler blood flow velocity measurement. A - before balloon isufflation, with normal cerebral flow; B - cerebral flow decrease after balloon insufflation; C - cranial ultrasonography to confirm balloon position and insufflation. 
Table 1. Average measures of intracranial variable during experiment.

\begin{tabular}{lcccccc} 
& T0 & T1 & T2 & T3 & T4 & T5 \\
\hline ICPp & 6.3 & 6.4 & 24 & 31 & 22 & 2 \\
ICPe & 6.8 & 7.1 & 9.1 & 33 & 19 & 3 \\
$\mathrm{PTiO}_{2}$ & 26 & 28 & 6,3 & 3,1 & 3,2 & 15.6 \\
$\mathrm{MAP}^{2}$ & 96 & 92 & 109 & 130 & 122 & 91 \\
\hline
\end{tabular}

ICPp: intracranial pressure (parenchymal); ICPe: intracranial pressure (epidural);PTiO2: cerebral oximetry; MAP: middle arterial pressure;T0: baseline measures; T1: before balloon insufflation; T2: after balloon insufflation, T3: 1.5 hour after balloon insufflations; T4: after saline solution infusion; T5: after balloon deflation.

mentioned that a negative CCI represents a physiological doctrine of Monro-Kellie that illustrates the volumetric compensation between CSF and arterial compartments, whereas positive values reflect doctrine disorders by increasing the volumes of both compartments. Clinical observations indicate that the A waves (plateau) and arterial hypertension were associated with negative CCI, and positive CCI was observed in refractory IH.

The skull is a semi-rigid structure with low elasticity that gradually decreases with age, as demonstrated by engineering experiments using strain gauges ${ }^{11-13}$. Like any substance, bone tissue has the physical property of elasticity. When ICP increases, it causes micrometric deformations of the skull bones.

According to the principles of the Monro-Kellie doctrine, there is an initial equilibrium between intracranial compartments, and dysfunction appears after intracerebral expansions. Groups A and C involved different volumes of continuous expansion, whereas Group B underwent discontinuous expansion to simulate lesion re-expansion. All animals were closely observed for changes for $1.5 \mathrm{~h}$ after the start of the expansion before a mock clinical intervention was performed (3\% hypertonic saline solution). After $30 \mathrm{~min}$, a mock surgical intervention was made (balloon deflation). The animals were observed for an additional hour before the experiment ended with the sacrificing of the animals and removal of the brain for macroscopic and histological analyses. The model allows the determination of a decrease in intracranial compliance by refractory IH.
Other previous studies have also used experimental swine models. Wagner et al. ${ }^{5}$ described a model with blood infusion in a balloon, but this method was not satisfactory because hematoma size was highly variable, and the model showed poor reproducibility. Shi et al. ${ }^{4}$ developed another model of intracranial hemorrhage in 24 pigs and studied histological changes in brain tissue after autologous blood infusion. However, that investigation did not assess acute cerebrovascular features.

IH parameters were evaluated by TCD through changes in systolic, diastolic, and MBP, in addition to the pulsatility index measured immediately before and after each intervention. A sudden change in mean MBP leads to a simultaneous change in cerebral blood flow initially, but it also triggers a number of other responses ${ }^{14}$. Thus, the assessment of cerebral hemodynamics in the acute phase of these conditions may contribute to more effective planning of therapeutic strategies for reducing secondary brain lesions ${ }^{15}$. In our model, it was possible to evaluate cerebrovascular vasoreactivity with TCD without problems in all tested animals. Additionally, the volume infused was confirmed by ultrasonography.

Regarding ICP measurement, epidural sensor placement for ICP monitoring has been discussed for many years as an important option because it has fewer complications compared to intraparenchymal pressure monitoring ${ }^{16-18}$. In our study, the pressures were similar in animals with the balloon uninflated. However, ICP latency was larger in epidural system. The existence of a significant drift and latency of epidural pressure system compared with parenchymal pressure system was first described by Powell and Crockard ${ }^{19}$. Raabe et al. ${ }^{20}$ also described this latency. The authors concluded that these drifting periods could be found during throughout the entire measurement. The biomechanical conditions in the epidural space can influence pressure distribution to the sensor and interfere with epidural pressure system measurements ${ }^{16,20}$.

The model described here seems useful for understanding some important pathophysiological characteristics of acute IH.

\section{References}

1. Andrade AF, Paiva WS, Amorim RL, Figueiredo EG, Rusafa Neto E, Teixeira MJ. The pathophysiological mechanisms following traumatic brain injury. Rev Assoc Med Bras. 2009;55(1):75-81.

2. Miller JD. Traumatic brain swelling and edema. In: Cooper PR (Ed). Head Injury. 3rd ed. New York: Morgan Hill, 1993:331-354.

3. Ryska O, Pantoflicek T, Laszikova E, Prazak J, Koblihova E, Ryska M. Artificial liver support system reduces intracranial pressure more effectively than bioartificial system: an experimental study. Int J Artif Organs 2012;35:503-510.
4.

Shi Y, Li Z, Zhang S, et al. Establishing a model of supratentorial hemorrhage in the piglet. Tohoku J Exp Med 2010;220:33-40.

5. Wagner KR, Xi G, Hua Y, et al. Lobar intracerebral hemorrhage mode in pigs: rapid edema development in perihematomal white matter. Stroke 1996;27:490-497.

6. Pourcyrous M, Parfenova H, Shibata M, Bada HS, Korones SB, Leffler CW. The effects of intraventricular-periventricular blood on cerebral 3,5'-cyclic adenosine monophosphate concentration and cerebrovascular reactivity in newborn pigs. Pediatr Res 1997;42:305-310. 
7. Friess SH, Ralston J, Eucker SA, Helfaer MA, Smith C, Marguiles SS. Neurocritical care monitoring correlates with neuropathology in a swine model of pediatric traumatic brain injury. Neurosurgery 2011;69:1139-1147.

8. Adams RD, Victor M. Principles of Neurology. $3^{\text {rd }}$ ed. New York: McGraw-Hill, Inc., 1985.

9. Kanter MJ, Narayan RK. Management of head injury. Intracranial pressure monitoring. Neurosurg Clin N Am 1991;2:257-265.

10. Kim DJ, Czosnyka Z, Kasprowicz M, et al. Continuous monitoring of the Monro-Kellie doctrine: is it possible? J Neurotrauma 2012;29:1354-1363

11. Geeraerts T, Merceron S, Benhamou D, Vigué B, Duranteau J. Non-invasive assessment of intracranial pressure using ocular sonography in neurocritical care patients. Intensive Care Med 2008;34:2062-2067.

12. Thees C, Scholz M, Schaller M D C, et al. Relationship between intracranial pressure and critical closing pressure in patients with neurotrauma. Anesthesiology 2002;96:595-599.

13. Panerai RB. The critical closing pressure of the cerebral circulation. Med Eng Phys 2003;25:621-632.

14. Bor-Seng-Shu E, Kita WS, Figueiredo EG, et al. Cerebral hemodynamics: concepts of clinical importance. Arq Neuropsiquiatr 2012;70:352-356.

15. Dagal A, Lam AM. Cerebral blood flow and the injured brain: how should we monitor and manipulate it? Curr Opin Anaesthesiol 2011;24:131-137.

16. Eide PK. Comparison of simultaneous continuous intracranial pressure (ICP) signals from ICP sensors placed within the brain parenchyma and the epidural space. Med Eng Phys 2008;30:34-40.

17. Bruder N, N'Zoghe P, Graziani N, Pelissier D, Grisoli F, François G. A comparison of extradural and intraparenchymatous intracranial pressures in head injured patients. Intensive Care Med 1995;21:850-852.

18. Paiva WS, de Andrade AF, Amorim RL, Figueiredo EG, Matushita $H$, Teixeira MJ. Intracranial pressure monitoring in children with fulminant hepatic failure. Rev Neurol 2009;48:134-136.

19. Powell MP, Crockard HA. Behavior of an extradural pressure monitor in clinical use. J Neurosurg 1985;63:745-749.

20. Raabe A, Totzauer R, Meyer O, Stöckel R, Hohrein D, Schöche J. Reliability of epidural pressure measurement in clinical practice: behavior of three modern sensors during simultaneous ipsilateral intraventricular or intraparenchymal pressure measurement. Neurosurgery 1998;43:306-311. 